\title{
A narrative review of alcohol consumption as a risk factor for global burden of disease
}

\author{
Jürgen Rehm ${ }^{1,2,3,4,5,6^{*}}$ (D) and Sameer Imtiaz ${ }^{1,3}$
}

\begin{abstract}
Since the original Comparative Risk Assessment (CRA) for alcohol consumption as part of the Global Burden of Disease Study for 1990, there had been regular updates of CRAs for alcohol from the World Health Organization and/or the Institute for Health Metrics and Evaluation. These studies have become more and more refined with respect to establishing causality between dimensions of alcohol consumption and different disease and mortality (cause of death) outcomes, refining risk relations, and improving the methodology for estimating exposure and alcohol-attributable burden. The present review will give an overview on the main results of the CRAs with respect to alcohol consumption as a risk factor, sketch out new trends and developments, and draw implications for future research and policy.
\end{abstract}

Keywords: Alcohol, Average level of consumption, Patterns of drinking, Comparative risk assessment, Relative risk, Burden of disease, Cause of death, Global

\section{Background}

The very first Global Burden of Disease (GBD) Study [1, 2] only gave indications on burden of disease as measured in number of deaths or disability adjusted life years ((DALYs; $[3,4])$ by different disease categories. DALYs are a summary gap measure of health combining fatal and non-fatal indicators, specifically summing up the years of life lost due to premature mortality and years of life lost due to disability [5]. The first GBD study was purely descriptive, but a major improvement from the situation in the past, when the sum of the number of deaths claimed by different causes by far exceeded the global number of deaths, even if only numbers within the same organization, such as the World Health Organization (WHO), were added up $[1,6]$. The second improvement of this study was that it was not restricted to fatal health outcomes, and with DALYs it included a summary measure combining fatal and non-fatal events [5].

\footnotetext{
* Correspondence: jtrehm@gmail.com

${ }^{1}$ Institute for Mental Health Policy Research, CAMH, 33 Russell Street, T505,

Toronto, ON M5S 2S1, Canada

${ }^{2}$ Campbell Family Mental Health Research Institute, CAMH, 250 College

Street, Toronto, ON M5T 1R8, Canada

Full list of author information is available at the end of the article
}

However, already at that stage it became apparent that more information was needed if one wanted to decrease the burden of disease. The concept of risk factor is key here [7]; defined as any attribute, characteristic or exposure of an individual that increases the likelihood of developing a disease or injury [8]. As a consequence, all future GBD studies included Comparative Risk Assessments (CRAs), which estimated the number of deaths and DALYs that could be avoided if certain risk factors were to be eliminated or shifted to a less detrimental distribution [9-12]. Such information was seen as important for health policy, especially in terms of primary prevention ([1, 13]; specifically for alcohol see [14, 15]). Alcohol consumption has always been part of the top 10 risk factors assessed in these CRAs in terms of the attributable global burden of disease.

This review will give an overview on the main results of the CRAs with respect to alcohol consumption, sketch out new trends and developments, and draw implications for future research and policy. 


\section{Alcohol-attributable burden of mortality and disease in the various Comparative Risk Assessments}

Table 1 gives an overview of the main CRAs conducted since 1996 on two main outcomes: all-cause mortality as measured in the number of deaths, and burden of disease as measured in DALYs (for a definition of DALYs see $[3,4])$.

While Table 1 seems to indicate a substantial rise in both alcohol attributable mortality and disease burden, this is not the case. Any CRA estimates depend very much on methodology, and the majority of the variation between the first estimate for 1990 [12] and the other estimates can be explained by the following factors (see also $[16,17]$ :

- Availability of and methodology used for cause of death and disability statistics on a global level.

- Diseases and causes of death which are seen as causally impacted by alcohol.

- Relative risk estimates used to estimate attributable disease burden.

- Methodology used to derive attributable fractions.

These questions will be discussed separately under different headings below.

Having clarified this, there have been efforts to estimate real changes using the same methodology for comparisons in global or regional alcohol-attributable burden of disease between 1990 and 2010 [10]; between 1990 and $2013[11,18]$ or between for all years from 1990 to $2014[19,20]$.

\section{Availability of and methodology used for cause of death and disability statistics on a global level}

Alcohol has been causally linked to more than 230 ICD 10 three digit disease categories [17], including about 40 that would not exist without alcohol (such as alcohol dependence or alcoholic liver cirrhosis; for a complete list see [21]). However, this does not mean, the various global CRA efforts are including all of these disease categories. First, global health statistics are not that detailed. For most of the population worldwide, there are no vital registries with cause of death information. The World Health Organization (WHO) estimates that vital registries fail to cover about two thirds, or 38 million out of 56 million annual deaths globally [22]. For the rest, i.e., the majority of cause of deaths globally, the basis are verbal autopsies and standardized algorithms to analyze these verbal autopsies and to scale up these results to wider regions [23]. Obviously, the resulting cause of death categories are fewer and broader than the categories of the ICD, as it is impossible to determine detailed cause of deaths via verbal autopsy [24]. As indicated above, burden of disease is composed of mortality and disability. For disability, the data situation is worse than for mortality [25], and estimates are developed based on estimated prevalence of disease categories [26] and disability weights; a disability weight is a factor that reflects the severity of the disease on a scale from 0 (perfect health) to 1 (equivalent to death) [27].

Currently, there are two different organizations which produce estimates for global data on health outcomes: the Institute for Health Metrics and Evaluation (IHME) [28] and the WHO [29]. Methodologies for estimating deaths are overlapping but different, resulting in different estimates on cause of death by categories (e.g., [30]). Secondly, different disability weights are applied for non-fatal outcomes, resulting in different estimates of burden of disease in DALYs ) [31-33]. However, the number of disease categories are the same between both organizations. For CRAs this means, that the number of deaths and DALYs, where attributable fractions are applied to, are different based on which underlying statistics are used. One of the main differences specifically for alcohol consumption as a risk factor are alcohol use disorders, which are defined differently by IHME and WHO, and where different disability weights have been applied (IHME restricted to dependence, WHO including harmful use of alcohol with a non-zero weight). A reconceptualization on heavy drinking over time may help overcome these differences [34].

Table 1 Proportion of global mortality and DALYs attributable to alcohol (net burden)

\begin{tabular}{|c|c|c|c|}
\hline Year & Proportion of global mortality attributable to alcohol & Proportion of global DALYs attributable to alcohol & Reference \\
\hline 1990 & $1.5 \%$ & $3.5 \%$ & {$[12,155]$} \\
\hline 2000 & $3.2 \%$ (W: $0.6 \% ;$ M: $5.6 \%)$ & $4.0 \%$ (W: $1.3 \% ;$ M: $6.5 \%)$ & {$[16,156]$} \\
\hline 2004 & $3.8 \%$ (W: $1.1 \%$; M: 6.3) & $4.6 \%$ (W: $1.4 \% ;$ M: $7.6 \%)$ & [157] \\
\hline 2010 & $5.2 \%$ (W: $3.1 \% ;$ M: $6.9 \%)$ & 3.9 \% (W: $2.0 \%$; M: $5.4 \%)$ & {$[10,18]^{a}$} \\
\hline 2012 & $5.9 \%$ (W: $4.0 \% ;$ M: $7.6 \%)$ & $5.1 \%$ (W: 2.3 \%; M: $7.4 \%)$ & [9] \\
\hline 2013 & $5.1 \%$ (W: $3.1 \% ;$ M: $6.8 \%)$ & $4.1 \%$ (W: $1.9 \%$; M: $5.9 \%)$ & {$[11,18]^{\mathrm{a}}$} \\
\hline 2015 & \multicolumn{3}{|c|}{ GBD 2015 and WHO Global Status Report on Alcohol and Health to be published in 2016} \\
\hline
\end{tabular}

${ }^{a}$ The given estimates for mortality are not available in the Lancet publications of the Global Burden of Disease Study 2010 and 2013 [10, 11 ]. They were obtained from GDB Compare [18]. Please note that these estimates may change when the methodology changes, so the date of assessment is important 
The availability of only broader categories on a global level has consequences for CRA. Diseases and causes of death like alcoholic cardiomyopathy or alcohol-induced chronic pancreatitis are relevant in many countries (for alcoholic cardiomyopathy: [35]; for pancreatitis: [36]), but there are no global statistics. As a consequence, the impact of alcohol can only indirectly be assessed by using larger categories such as cardiomyopathy or pancreatitis, for which global estimates exist. Unfortunately, often risk relations are missing for such larger categories: this is the case for cardiomyopathy, as there is neither a systematic review nor a meta-analyses for the impact of alcohol, and thus, this category will show no alcohol-attributable cases, even though we know, there are cases of alcoholic cardiomyopathy. For alcoholinduced chronic pancreatitis, the CRA has to rely on the larger category of pancreatitis and meta-analyses on the impact of alcohol on this category $[37,38]$ to be included into alcohol-attributable deaths or burden of disease. As a consequence, the alcohol-attributable disease and cause of death categories boil down to a much lower number of less than 25. In sum, global estimates on alcohol-attributable mortality and disease burden rely only on selected large disease categories. This eliminates most categories, which are $100 \%$ alcohol-attributable by definition, except for alcohol use disorders and fetal alcohol syndrome (for some background on burden attached for alcohol use disorders: [39, 40]; for fetal alcohol syndrome [41]), as well as smaller partially attributable categories of disease or causes of death.

\section{Diseases and causes of death seen as causally impacted by alcohol}

The number of alcohol-attributable disease categories in CRAs over the past decades has been increasing for three reasons. First, while the overall number is still small, more disease categories have been included into the global statistics (both as cause of death and as burden of disease in DALYs). To give two examples relevant for alcohol, pancreatitis and cardiac arrhythmias were added for the CRA of GBD study 2010 [17, 24]. Second, evidence on the causal impact of alcohol consumption became stronger and more convincing for certain disease categories, and third, better models for quantification of such causal impact were established.

\section{Alcohol-attributable cancers}

For the second reason specified above, take alcoholattributable cancers as an example [42]. While the first monograph from the meeting of the International Agency for Research on Cancer on alcohol use and cancer established sufficient evidence for a causal relationship between alcohol consumption and the cancer categories of nasopharyngeal cancer, esophageal cancer, laryngeal cancer, and liver cancer [43], the next meeting added female breast and colorectal cancers $[44,45]$. The underlying evidence led to inclusion of breast cancer into the CRAs from the GDB study 2000 onwards, and for colorectal cancers from 2010 onwards. Currently other types of cancer are discussed as potentially alcohol-attributable, such as cancer categories of pancreas or stomach cancer, as heavy drinking has been consistently associated with increased risk for these categories [46, 47]; thus, more cancer categories will likely be added to future CRAs.

\section{Alcohol-attributable infectious diseases and causes of death} Of the alcohol-attributable disease categories, infectious diseases and causes of death constitute the most important overall change within the past two decades. Even though pneumonia and tuberculosis had been seen as impacted by heavy drinking as early as in the $18^{\text {th }}$ century [48], the causality had to be re-established using current criteria [49]. The first step was conducted in a consensus meeting in 2008, which established causality for tuberculosis and pneumonia [50]. This led to inclusion of these categories from 2010 onwards (underlying documentation: tuberculosis [51]; pneumonia [52]).

The open question was HIV/AIDS, where the meeting did not find enough evidence of causality despite consistent associations [53-55]. There was a clear causal association which could be quantified for one pathway: the impact of alcohol consumption on medication adherence, which had impact on mortality [56]. This association was implemented for the 2012 CRA, which was the basis of the WHO 2014 Global status report [9]. Moreover, in a number of recent systematic reviews based on experimental research, it could be established that alcohol has a causal impact on decisions to engage in unsafe sex $[57,58]$. This allows for estimation of alcohol impacting the incidence of HIV as an additional component in future CRAs, and the responsible WHO technical advisory group has decided to include this component. This addition will markedly change the estimates of alcohol-attributable mortality and burden of disease in Sub-Saharan Africa [59].

\section{Alcohol use and mental disorders}

It may be surprising that since 2010 no other mental disorders than alcohol use disorders have been included (i.e., alcohol dependence and the harmful use of alcohol according to ICD 10). Clearly most mental disorders have consistent associations with alcohol use, especially heavy drinking, and alcohol use disorders (e.g., [60-62]; we give only references for alcohol use disorders, as heavy drinking is very closely related to these disorders [63], and has even been suggested as a better definition for kind of disorders [64]). In addition to these associations, both 
DSM-5 and ICD $10[65,66]$ list alcohol-induced mental disorders, thus establishing causality. However, there is a problem in quantifying the causal impact. While alcohol consumption impacts mental disorders, there is also reverse causality, and we cannot exclude genetic vulnerability as a third variable impacting both alcohol consumption and mental disorders [16]. Thus, quantification of causality is difficult. It has been attempted in the GBD study 2000 for major depressive disorders [16], but later committees did not see this attempt as convincing enough. Maybe some of the newer research on alcohol and depression $[67,68]$ will allow for better modelling in future CRAs.

\section{Other alcohol-attributable disease and injury categories}

Other categories of alcohol-attributable disease and mortality included in current CRAs are fetal alcohol syndrome (by definition), epilepsy [69], gastrointestinal disease (liver cirrhosis [70] and pancreatitis [37, 38]; the latter new for the CRA associated with GBD study 2010 and after), diabetes [71], cardiovascular disease [72] hypertensive disease [73], ischemic heart disease [74], stroke [75], and cardiac arrhythmias [76], the last one new for the CRAs 2010 and after, and almost all categories of injury $[77,78]$. The last systematic overview on alcohol use and causal relations to different disease and cause of death categories can be found in [17].

The alcohol-attributable burden in all CRAs has almost entirely been estimated as the effect of drinking on the drinkers themselves. However, as with smoking, there is significant harm to others [79, 80] (for some first estimation within a CRA: [81]). In the CRAs thus far, only some of the effect of mothers' drinking on newborns (in the last CRAs only fetal alcohol syndrome; before low birth weight - [82]) and unsystematically some of the effects on harm to others in traffic injuries have been captured.

In sum, with respect to changes of alcohol-attributable disease categories over time, there have been some categories added since 1990, mainly based on more disease categories available on a global basis. In addition, the evidence base has expanded in recent years to include and quantify the contribution of infectious disease categories as being alcohol-attributable. However, effects of alcohol consumption on others than the drinker have not been covered systematically.

\section{Relative risk estimates used to estimate attributable disease burden}

Table 2 gives an overview on the relative risk estimates used for the WHO Global status report on alcohol and health [9] for all countries except for Russia and surrounding countries (for graphical displays of the dose-response relationships between average volume of consumption and outcomes see [83]; for the estimates used for Russia and surrounding countries see [84]).

While new meta-analyses on the risk relations between level of consumption and various disease/mortality outcomes appear regularly, this does not change the burden estimates dramatically. Take breast cancer as an example: there have been more than 100 single studies and 16 systematic reviews with meta-analyses over the past 20 years [85]. However, the main conclusions on relative risk did not change: there is a clear dose-response relationship with no protective effect for any level of drinking compared to lifetime abstainers [85]. Even drinking as low as one drink on average is associated with increased risk for breast cancer $[85,86]$. The quantification for the different levels of alcohol-attributable risk for breast cancer had been quite similar over the years [85], as they had been for cancer in general (e.g., [87], which has been used to date for the CRAs, and [47]; which will be used in the future).

The field of cardiovascular outcomes has been less stable, in part, because two dimensions of alcohol consumption need to be taken into consideration, average volume and patterns of drinking, in particular heavy drinking occasions (in general: [88]; for cardiovascular in particular see $[16,89])$, and because there are much fewer underlying studies (for some endpoints less than 10 studies; see the underlying studies on heavy drinking occasions and ischemic heart disease: [74, 90]), and because part of the effect is on acute drinking and part on chronic drinking with different methodologies which are hard to reconcile in meta-analytic approaches (acute drinking risks have been mainly measured via casecrossover studies such as [91]; chronic risks have been mainly measured in cohort studies such as [92]). Another problem is the fact that risk curves differ between fatal and non-fatal outcomes for many endpoints such as stroke [75] or ischemic heart disease [89]. Overall this makes the estimation of alcohol-attributable mortality and burden of disease challenging, and in almost each new CRA, a different approach has been used. As well, newest calculations in the WHO European Region suggest, that relatively small changes in exposure resulted in marked changes of cardiovascular mortality over the past 25 years [20].

Relative risks for other outcomes can be classified as in between cancer and cardiovascular disease in their complexity. For many outcomes, fatal and non-fatal risk relations differ. Thus, it has been found that for liver cirrhosis, the risk curves are steeper (more exponential) for mortality compared to non-fatal outcomes [70]. The explanation is simple: it takes quite a lot of alcohol consumption to cause liver cirrhosis often via different stages of liver disease [93], but once liver cirrhosis is established, no matter of what etiology, relatively small 
Table 2 Categories of alcohol-attributable diseases and the sources used for determining risk relations from the WHO 2014 Global Status Report on Alcohol and Health [9] ${ }^{a}$

\begin{tabular}{|c|c|c|}
\hline Condition & ICD 10 Code & $\begin{array}{l}\text { Sources of risk relations (for calculating } \\
\text { alcohol-attributable fractions) }\end{array}$ \\
\hline \multicolumn{3}{|l|}{ Infectious and parasitic diseases } \\
\hline Tuberculosis & A15-A19 & [158] \\
\hline $\begin{array}{l}\text { Human immunodeficiency virus/ } \\
\text { Acquired immune deficiency syndrome }\end{array}$ & B20-B24 & $\begin{array}{l}\text { [56] for estimate on the impact of alcohol on } \\
\text { worsening the disease course via disrupting } \\
\text { the medication schedule }\end{array}$ \\
\hline \multicolumn{3}{|l|}{ Malignant neoplasms } \\
\hline Mouth and oropharynx cancers & $\mathrm{C} 00-\mathrm{C} 14$ & (based on relative risks from [87]) \\
\hline Esophageal cancer & $\mathrm{C} 15$ & (based on relative risks from [87]) \\
\hline Liver cancer & $\mathrm{C} 22$ & (based on relative risks from [87]) \\
\hline Laryngeal cancer & C32 & (based on relative risks from [87]) \\
\hline Breast cancer & C50 & (based on relative risks from [87]) \\
\hline Colon cancer & C18 & (combined risk taken from [47]) \\
\hline Rectal cancer & C20 & \\
\hline \multicolumn{3}{|l|}{ Diabetes } \\
\hline Diabetes mellitus & E10-E14 & [71] \\
\hline \multicolumn{3}{|l|}{ Neuro-psychiatric conditions } \\
\hline Alcoholic psychoses (part of AUD) & F10.0, F10.3-F10.9 & $100 \%$ alcohol attributable by definition \\
\hline Alcohol abuse (part of AUD) & F10.1 & \\
\hline Alcohol dependence (part of AUD) & F10.2 & \\
\hline $\begin{array}{l}\text { Accidental poisoning by and exposure } \\
\text { to alcohol }\end{array}$ & $x 45$ & \\
\hline Epilepsy & G40-G41 & {$[69]$} \\
\hline \multicolumn{3}{|l|}{ Cardiovascular disease } \\
\hline Hypertensive disease & $\mid 10-115$ & [73] \\
\hline Ischemic heart disease & $120-125$ & {$[89,90,159]$} \\
\hline \multicolumn{3}{|l|}{ For any CRA after GBD 2013 see: [89] } \\
\hline Cardiac arrhythmias & $147-149$ & [76] \\
\hline Ischemic stroke & $160-162$ & {$[75,89]$} \\
\hline Hemorrhagic and other non-ischemic stroke & $163-166$ & [75] \\
\hline \multicolumn{3}{|l|}{ Digestive diseases } \\
\hline Cirrhosis of the liver & K70, K74 & [70] \\
\hline Acute and chronic pancreatitis & K85, K86.1 & {$[37]$} \\
\hline \multicolumn{3}{|l|}{ Respiratory infections } \\
\hline Lower respiratory infections & $J 10-J 18, J 20-J 22$ & [52] \\
\hline \multicolumn{3}{|l|}{ Conditions arising during the prenatal period } \\
\hline Fetal alcohol syndrome & Q86.0 & $100 \%$ alcohol attributable by definition \\
\hline \multicolumn{3}{|l|}{ Unintentional injuries } \\
\hline Motor vehicle accidents & b & [87] \\
\hline Poisonings & X40-X49 except X45 & {$[87]$} \\
\hline Falls & W00-W19 & [87] \\
\hline Fires & X00-X09 & {$[87]$} \\
\hline Drowning & W65-W74 & {$[87]$} \\
\hline
\end{tabular}


Table 2 Categories of alcohol-attributable diseases and the sources used for determining risk relations from the WHO 2014 Global Status Report on Alcohol and Health [9] ${ }^{\mathrm{a}}$ (Continued)

\begin{tabular}{|c|c|c|}
\hline Other Unintentional injuries & $\begin{array}{l}{ }^{c} \text { Rest of V-series and W20-W64, } \\
\text { W 75-W99, X10-X39, X50-X59, } \\
\text { Y40-Y86, Y88, Y89 }\end{array}$ & [87] \\
\hline tentional injuries & & [87] \\
\hline Self-inflicted injuries & X60-X84, Y87.0 & [87] \\
\hline Homicide & X85-Y09, Y87.1 & [87] \\
\hline
\end{tabular}

\begin{abstract}
${ }^{a}$ Due to lack of data on very specific categories of death, diseases where alcohol is a necessary cause (other than Alcohol Use Disorders), such as alcohol poisonings, were modelled using RRs for the broader category

${ }^{b}$ V021-V029, V031-V039, V041-V049, V092, V093, V123-V129, V133-V139, V143-V149, V194-V196, V203-V209, V213-V219, V223-V229, V233-V239, V243-V249, V253-V259, V263-V269, V273-V279, V283-V289, V294-V299, V304-V309, V314-V319, V324-V329, V334-V339, V344-V349, V354-V359, V364-V369, V374-V379, V384-V389, V394-V399, V404-V409, V414-V419, V424-V429, V434-V439, V444-V449, V454-V459, V464- V469, V474-V479, V484-V489, V494-V499, V504-V509, V514-V519, V524-V529, V534-V539, V544-V549, V554-V559, V564-V569, V574-V579, V584-V589, V594-V599, V604-V609, V614-V619, V624-V629, V634-V639, V644-V649, V654- V659, V664-V669, V674-V679, V684-V689, V694-V699, V704-V709, V714-V719, V724-V729, V734-V739, V744-V749, V754-V759, V764-V769, V774-V779, V784-V789, V794-V799, V803-V805, V811, V821, V830-V833, V840-V843, V850- V853, V860-V863, V870-V878, V892 ${ }^{\mathrm{C}}$ Rest of $\mathrm{V}=\mathrm{V}$-series MINUS ${ }^{\mathrm{b}}$
\end{abstract}

amounts of alcohol may be fatal [70, 94]. Heavy drinking occasions may play an additional role here, but we do not have enough data to quantify this relationship [95].

Similarly, for injury, acute alcohol use has been linked to more severe and in particular to fatal injuries $[16,96]$. For CRA this means that different risk relations have to be used for mortality and for the non-fatal outcomes.

One of the main problems with the relative risks is that it is assumed, that they are biological constants and the same for all countries, and thus it does not matter, that the current estimates are derived from metaanalyses of select cohort studies from a few high income countries with a limited variation of drinking patterns (see above and [97], box on "Methodological issues relevant to studies of alcohol-related morbidity and mortality). Unfortunately, this assumption is not correct. It has been shown that the usual relative risks derived differ from the analogous risks found in Russia or surrounding countries [98, 99], and thus would lead to underestimates of alcohol-attributable burden [100]. In the most recent CRAs after 2010, this has been acknowledged and country specific relative risks have been used [84]. We suspect that different relative risks could be necessary for other countries with high per capita consumption per drinker (see [9], for a listing of countries), or for countries with irregular heavy-drinking patterns (e.g., countries with festive drinking such as Mexico; $[101,102])$. Unfortunately, as of now, we have no evidence base to implement country- or region-specific relative risks for these patterns. Another problem is genetic predisposition, which sometimes interacts with alcohol consumption to produce different risks. As an example, the flushing gene [103], which is clearly associated with higher risks for alcohol-attributable cancer with an acetaldehyde pathway [104], clearly indicated different relative risk estimates for countries where this genetic constellation is prevalent (such as China, Japan and South Korea).
In sum, global estimates of risk relations tend to only minimally change for outcomes with many underlying studies such as cancer outcomes. This changes for cardiovascular outcomes, where more than one exposure dimension is relevant, and where there are few studies to quantify the risk relations. In future, more countryor region-specific relative risk estimates will be necessary to include genetic variability and more extreme drinking patterns, which are not measured in most cohort studies (see the box on "Methodological issues relevant to studies of alcohol-related morbidity and mortality" and [97] for further discussion of the limitations of cohort studies).

\section{Methodology used to derive attributable fractions}

While the overall methodology for CRAs has been fairly stable (for a description see $[105,106]$ ) based on original epidemiological concepts of the 1980s [107, 108], there are important shifts in details:

- The first CRAs until and including the 2010 study were based on discrete categories of exposure and associated relative risks, whereas the latter were based on a continuous distribution of both exposure and risk (for theoretical background: [109]; for a comparison of both methods in the same sample: [110])

- This implicated different ways to define exposure and to triangulate between national per capita consumption and surveys (see $[16,111]$ and $[110,112]$ for the categorical, and the continuous approach respectively). However, the differences between the categorical and the continuous approach for alcohol as a risk factor in CRAs are not that large [109].

- The biggest difference will come in via the triangulation of survey and per capita consumption. Overall per capita consumption is considered as 
most validly representing the overall consumption level in a population [113], especially if it is for countries with high proportion of recorded consumption ( [9] for the proportion of recorded to overall consumption). However, as per capita consumption is derived from administrative records [114], it allows no differentiation by sex and age. That is where surveys become indispensable. The problem is that general population surveys only cover part of the real consumption, and this proportion, usually labelled coverage rate $[115,116]$, is highly variable. The known variation of coverage rates is between $20 \%$ and $90 \%$ (for an example of low coverage: $27 \%$ in Canada [117]; for high coverage see $87 \%$ in Sweden [118] or close to $90 \%$ in New Zealand [119]).

- So triangulation basically assumes the distribution by sex and age of the survey, and a consumption level of $80 \%$ of the per capita consumption [110]. The reason for not assuming $100 \%$ of per capita consumption which is sold is, that there is some spillage and other waste of alcohol, and that exposure is applied to risk relation estimates which may also underestimate consumption. However, the degree of underestimation is not clear, as there is no gold standard for such studies. There are some indications that cohort studies with their specific forms of assessment often in a medical environment tend to show less underestimation of true consumption [120-122]. Moreover, lack of coverage does not only reflect individuals underestimating or misrepresenting their consumption. It also reflects the sample frame of the survey, which usually excludes high drinking populations such as military or institutionalized people [123]. As a result it is hard to calibrate a certain proportion of per capita consumption, but the WHO technical advisory committee after reviewing all the underlying evidence decided for $80 \%$. The impact of different triangulations can be considerable [117, 124], so it is good to be conservative [125].

\section{Implications for research}

In the above, we described the methodology to conduct a CRA for alcohol consumption. In this methodology, instantaneous effects are assumed: i.e., exposure to alcohol consumption in a certain year is assumed to result in changes in mortality for this year. This clearly is a simplification, as there is usually a lag time between alcohol consumption and disease outcomes [126]. Moreover, individual consumption may vary, and many risk relations assume more or less a constant consumption over time [127]. Future CRAs should address this problem and take into consideration the lag time between consumption and outcomes (e.g., using methodology such as $[128,129])$. However, such a step would need a reconfiguration of the conceptual model for all CRAs for all risk factors, as one of the main objectives of any CRA is to be comparative between risk factors and time.

In addition we expect the following methodological changes for future CRAs for alcohol:

- With respect to modelling exposure, methods to triangulate irregular heavy drinking occasions with per capita consumption are needed. As indicated above, currently the only triangulation is between average level of alcohol consumption and per capita consumption [110, 112]. For irregular heavy drinking occasions [130, 131], we accept self-reports from surveys as true, even if we know, that they usually underestimate true frequency and number of drinks per occasion. In the future, we need to develop ways to triangulate self-report and objective measurement for irregular heavy drinking occasions.

- We have already mentioned the rather strong assumption, that risk relations taken from the most comprehensive meta-analysis are seen as a global constant with exception of Russia and surrounding countries (where the risk relations are based on [98, 99]; see also [84]). Given the genetic and environmental differences, we would expect some differences in risk relations between alcohol consumption and disease/mortality outcomes in different regions (e.g. based on the interaction between genetics and alcohol consumption in causing cancer; see [104, 132]). Future CRAs for alcohol consumption will have to more and more regionalize risk relations, not only based on genetic predisposition, but also based on socially determined risks such as the risks for injury outcomes [133, 134].

- Finally, we expect that future CRAs will have explicit separation on harm to drinkers and harm to others. The conceptual framework is there [135], the underlying data for major categories such as traffic injury [136] or for fetal alcohol syndrome/ fetal alcohol spectrum disorders is there (the latter estimated via drinking in pregnant women; $[137,138])$ and there are major efforts to improve the methodology for quantification (e.g., in the Netherlands based on the per se law on substance use and violence - [139]; in Germany within a comprehensive effort to estimate alcoholattributable harm to others for the Ministry personal communication of Prof. L. Kraus). 


\section{Implications for alcohol policy}

As indicated above, all CRAs resulted in marked burden of disease caused by alcohol consumption. Two dimensions were identified as important to cause harm: overall level of consumption and patterns of drinking [88]. Policies need to address both dimensions.

There are effective and cost-effective policies to lower overall level of consumption in societies [140, 141], such as the so-called 'best buys', i.e., increase of taxation leading to increases in price of alcoholic beverages, decrease in availability, and ban of marketing and advertisement $[142,143]$. However, these policies do not to seem to be too popular with governments, and in fact alcohol has become more available and affordable in most parts of the world over the past decades (e.g., in the European Union, see [144]). Other potential ways to decrease overall level of alcohol consumption would be a decrease in alcoholic strength, which is technically possible for all beverages, and which could be achieved via government regulation, taxation or industry initiatives [145]. It should be noted however, that a reduction in overall level of alcohol consumption does not necessarily mean a reduction in total alcohol-attributable mortality or burden of disease, as monitoring of the last 25 years for the WHO European Region has shown [20]. In addition, it has to be assured, that the heaviest drinkers do not increase their drinking (e.g., via treatment [146]), and that patterns of drinking do not get worse (see also [20]).

Regarding patterns of drinking, there are other promising policies such as minimum pricing $[147,148]$, and specific policies to decrease heavy drinking occasions in certain situation, such as in participation in traffic [136] or while operating machinery at the workplace [149]. Obviously, harm would be minimized, if in such situations abstinence was the norm.

Finally, the composition of alcohol-attributable burden of disease and mortality will have different implications for policy [150]. A high proportion of traffic injury could be reduced with specific measures for drink driving such as introduction and enforcement of a per se law regarding blood alcohol concentration, or reduction of the blood alcohol concentration threshold in existing laws $[140,151]$. On the other hand, high alcohol-attributable intentional injury will ask for specific measures such as measures against binge drinking or per se laws on criminal prosecution [150]. To give one final example concerning chronic disease: high levels of alcoholattributable liver disease mortality point to high overall level of consumption [152, 153], or to relatively high level of consumption combined with other etiological factors for liver disease such as HIV (as even comparatively small levels of alcohol consumption may cause liver mortality in people with liver cirrhosis no matter which etiology - see above for further detail and [20], for examples). Reductions of overall alcohol consumption, no matter how achieved, will lead to reductions in alcohol-attributable liver mortality [20].

\section{Conclusions}

The CRA methodology has been evolving and for comparisons over time it is necessary to use the latest methodology and calculate backwards using the same methodology. If this principle is used, then CRAs can potentially inform the health policy process and yield important information for decision makers. Obviously, interventions will depend not only on the size and shape of the burden, but also on how much of the alcohol-attributable burden is avoidable [154], and on aspects on feasibility, costs and cost-effectiveness of interventions $[14,15]$. For alcohol consumption, in principle all of the burden is avoidable, but any intervention will have to take into consideration the role alcohol has been playing in our society for thousands of years [13]. However, despite these general limitations, information about attributable burden will also be one major building block towards better policies $[19,150]$.

\section{Abbreviations \\ AIDS: Acquired Immune Deficiency Syndrome; AUD: Alcohol Use Disorder; CRA: Comparative Risk Assessment; DALYs: Disability Adjusted Life Years; DSM: Diagnostic and Statistical Manual of Mental Disorders; GBD: Global Burden of Disease; HIV: Human Immunodeficiency Virus; ICD: International Classification of Disease; IHME: Institute for Health Metrics and Evaluation; WHO: World Health Organization}

\section{Acknowledgments}

We would like to thank more than 1000 collaborators who helped in the various CRAs by contributing data and comments.

\section{Funding}

The first author received grants and contracts from NIAAA (contract \# HHSN267200700041C and various amendments), the WHO and the Global Burden of Disease study for contributions to the Comparative Risk Assessment for 2000, and all other CRAs since.

\section{Availability of data and materials}

This is a review of published materials. The original underlying data can be found at the websites of the Institute for Health Metrics and Evaluation (http://www.healthdata.org/) and the WHO Global Information System on Alcohol and Health (http://www.who.int/gho/alcohol/en/). All specific sources cited are referenced in the text.

\section{Authors' contributions}

JR did a first draft of the paper. SI collected the information for Table 1. Both authors helped in revising the manuscript and approved of the final draft.

Competing interest

The authors declare that they have no competing interests.

Consent for publication

Not applicable.

Ethics approval and consent to participate

This is a narrative review of published sources. No ethical approval was necessary. Consent to participate is not applicable. 


\section{Author details}

'Institute for Mental Health Policy Research, CAMH, 33 Russell Street, T505, Toronto, ON M5S 2S1, Canada. ${ }^{2}$ Campbell Family Mental Health Research Institute, CAMH, 250 College Street, Toronto, ON M5T 1R8, Canada. Institute of Medical Science (IMS), University of Toronto, Medical Sciences Building, 1 King's College Circle, Room 2374, Toronto, ON M5S 1A8, Canada. ${ }^{4}$ Department of Psychiatry, University of Toronto, 250 College Street, 8th Floor, Toronto, ON M5T 1R8, Canada. ${ }^{5}$ Dalla Lana School of Public Health, University of Toronto, 155 College Street, 6th Floor, Toronto, ON M5T 3M7, Canada. ${ }^{6}$ Institute for Clinical Psychology and Psychotherapy, TU Dresden, Chemnitzer Str. 46, 01187 Dresden, Germany.

Received: 28 July 2016 Accepted: 19 October 2016 Published online: 28 October 2016

\section{References}

1. Murray CJL, Lopez AD, Jamison DT. The global burden of disease in 1990: summary results, sensitivity analysis and future directions. WHO Bulletin. 1994;72:496-509.

2. World Bank. World Development Report 1993 - Investing in Health. New York, ISBN 0-19-520890-0: 1993.

3. Murray CJ, Acharya AK. Understanding DALYs. J Health Econ. 1997;16:703-30.

4. Murray CJL. Quantifying the burden of disease: the technical basis for disability-adjusted life years. Bull World Health Org. 1994;72:429-45.

5. Murray CJL, Salomon J, Mathers C, Lopez A. Summary measures of population health: Concepts, ethics, measurement and applications. Geneva: World Health Organization; 2002.

6. Lopez AD. Cause of death in industrial and developing countries: estimates for 1985-1990. In: Jamison DT, Mosley WH, Measham AR, Bobadilla JL, editors. Disease Control Priorities in Developing Countries. Oxford: Oxford University Press (for the World Bank); 1993. p. 35-50.

7. Ezzati M, Lopez A, Rodgers A, Murray CJL. Comparative quantification of health risks. Global and regional burden of disease attributable to selected major risk factors. Geneva: World Health Organization; 2004.

8. World Health Organization. Risk Factors. 2016. http://www.who.int/topics/ risk_factors/en/. Accessed 26 Sept 2016

9. World Health Organization. Global status report on alcohol and health. Geneva: World Health Organization; 2014.

10. Lim SS, Vos T, Flaxman AD, Danaei G, Shibuya K, Adair-Rohani H, et al A comparative risk assessment of burden of disease and injury attributable to 67 risk factors and risk factor clusters in 21 regions, 1990-2010: a systematic analysis for the Global Burden of Disease Study 2010. Lancet. 2012; 380:2224-60

11. Forouzanfar $M H$, Alexander $L$, Anderson $H R$, Bachman VF, Biryukov $S$, Brauer $\mathrm{M}$, et al. Global, regional, and national comparative risk assessment of 79 behavioural, environmental and occupational, and metabolic risks or clusters of risks in 188 countries, 1990-2013: a systematic analysis for the Global Burden of Disease Study 2013. Lancet. 2015:386:2287-323.

12. Murray CIL, Lopez A. Quantifying the burden of disease and injury attributable to ten major risk factors. In: Murray $C J$, Lopez AD, editors. The Global Burden of Disease: A Comprehensive Assessment of Mortality and Disability from Diseases, Injuries and Risk Factors in 1990 and Projected to 2020. Boston: Harvard School of Public Health on Behalf of the World Health Organization and the World Bank; 1996. p. 295-324.

13. Anderson P, Braddick F, Conrod P, Gual A, Hellman M, Matrai S, et al. The New Governance of Addictive Substances and Behaviours. Oxford: Oxford University Press; 2016

14. Chisholm D, Rehm J, van Ommeren M, Monteiro M. Reducing the global burden of hazardous alcohol use: a comparative cost-effectiveness analysis. J Stud Alcohol. 2004;65:782-93.

15. Chisholm D, Doran C, Shibuya K, Rehm J. Comparative cost-effectiveness of policy instruments for reducing the global burden of alcohol, tobacco and illicit drug use. Drug Alcohol Rev. 2006;25:553-65.

16. Rehm J, Room R, Monteiro M, Gmel G, Graham K, Rehn N, et al. Alcohol Use. In: Ezzati M, Lopez AD, Rodgers A, Murray CJL, editors. Comparative quantification of health risks: global and regional burden of disease attributable to selected major risk factors. Geneva: World Health Organization; 2004. p. 959-1109.

17. Rehm J, Borges G, Gmel G, Graham K, Grant B, Parry C, et al. The comparative risk assessment for alcohol as part of the Global Burden of Disease 2010 study: What changed from the last study? Int J Alcohol Drug Res. 2013;2:1-5.
18. Institute for Health Metrics and Evaluation. GBD Compare. 2015. http://vizhub.healthdata.org/gbd-compare. Accessed 19 July 2016

19. Shield KD, Rylett M, Rehm J. Public health gains and missed opportunities Trends in alcohol consumption and attributable mortality in the WHO European Region, 1990-2014: A Report to the WHO European Region. Toronto, Canada: Centre for Addiction and Mental Health; ISBN - 978-177114-367-7. 2016

20. Shield KD, Rylett M, Rehm J. Public health successes and missed opportunities. Trends in alcohol consumption and attributable mortality in the WHO European Region, 1990-2014. Copenhagen: WHO European Region; 2016.

21. Shield KD, Popova S, Rehm J. The burden of disease and injury caused by alcohol. Reference Module in Biomedical Sciences. Elsevier online via science direct. doi: 10.1016/B978-0-12-801238-3.03188-3. Reference Module in Biomedical Sciences, Elsevier online via science direct. 2015.

22. World Health Organization. Civil registration: why counting births and deaths is important. Geneva, Switzerland: World Health Organization; 2014. http://www.who.int/mediacentre/factsheets/fs324/en/. Accessed 19 July 2016

23. Murray CJ, Lozano R, Flaxman AD, Serina P, Phillips D, Stewart A, et al. Using verbal autopsy to measure causes of death: the comparative performance of existing methods. BMC Med. 2014;12:5.

24. Rehm J, Mathers C. Global comparative risk assessment - what level of detail can be achieved? Lancet. 2009;374:477.

25. Goerdt A, Koplan J, Robine J, Thuriaux M, van Ginneken J. Non-fatal health outcomes: Concepts, instruments and indicators. In: Murray C, Lopez A, editors. The Global Burden of Disease: A Comprehensive Assessment of Mortality and Disability from Diseases, Injuries and Risk Factors in 1990 and Projected to 2020. Boston: Harvard School of Public Health on behalf of the World Health Organization and the World Bank; 1996. p. 99-117.

26. Flaxman AD, Vos T, Murray CJL. An Integrative Metaregression Framework for Descriptive Epidemiology. Washington: University of Washington Press; 2015.

27. Rehm J, Frick U. Valuation of health states in the U.S. study to establish disability weights: lessons from the literature. Int J Methods Psychiatr Res. 2010;19:18-33.

28. Institute for Health Metrics and Evaluation. Global Burden of Disease (GBD). 2016. http://www.healthdata.org/gbd. Accessed 19 July 2016.

29. World Health Organization. Global Health Estimates (GHE). 2016. http://www. who.int/healthinfo/global_burden_disease/en/. Accessed 19 July 2016.

30. Kovacs SD, Mullholland K, Bosch J, Campbell H, Forouzanfar MH, Khalil I, et al. Deconstructing the differences: a comparison of GBD 2010 and CHERG's approach to estimating the mortality burden of diarrhea, pneumonia, and their etiologies. BMC Infectious Disease. 2015;16:16.

31. Salomon JA, Vos T, Hogan DR, Gagnon M, Naghavi M, Mokdad A, et al. Common values in assessing health outcomes from disease and injury: disability weights measurement study for the Global Burden of Disease Study 2010. Lancet. 2012;380:2129-43.

32. Salomon JA, Haagsma JA, Davis A, de Noordhout CM, Polinder S, Havelaar AH, et al. Disability weights for the global burden of disease 2013 study. Lancet Global Health. 2015;3:e712-23.

33. Burstein R, Fleming T, Haagsma J, Salomon JA, Vos T, Murray CJ. Estimating distributions of health state severity for the global burden of disease study. Popul Health Metr. 2015;18:31.

34. Rehm J. How should prevalence of alcohol use disorders be assessed globally? Int J Methods Psychiatr Res. 2016;25:79-85.

35. Guzzo-Merello G, Cobo-Marcos M, Gallego-Delgado M, Garcia-Pavia P. Alcoholic cardiomyopathy. World J Cardiol. 2014;6:771-81.

36. Majumder S, Chari ST. Chronic pancreatitis. Lancet. 2016;387:1957-66.

37. Irving HM, Samokhvalov A, Rehm J. Alcohol as a risk factor for pancreatitis. A systematic review and meta-analysis. JOP. 2009;10:387-92.

38. Samokhvalov AV, Rehm J, Roerecke M. Alcohol consumption as a risk factor for acute and chronic pancreatitis: a systematic review and a series of meta-analyses. EBioMedicine. 2015;2:1996-2002.

39. Rehm J, Dawson D, Frick U, Gmel G, Roerecke M, Shield KD, et al. Burden of disease associated with alcohol use disorders in the United States. Alcohol Clin Exp Res. 2014;38:1068-77.

40. Samokhvalov AV, Popova S, Room R, Ramonas M, Rehm J. Disability associated with alcohol abuse and dependence. Alcohol Clin Exp Res. 2010;34:1871-8.

41. Popova S, Lange S, Shield KD, Mihic A, Chudley AE, Mukherjee RAS, et al. Co-morbidity of fetal alcohol spectrum disorder: a systematic literature review and metaanalysis. Lancet. 2016;387:978-87. 
42. Rehm J, Shield K. Alcohol consumption. In: Steward BW, Wild CP, editors World Cancer Report. Lyon: International Agency for Research on Cancer; 2014. p. 97-107.

43. International Agency for Research on Cancer. Alcohol Drinking. Lyon: International Agency for Research on Cancer; 1988.

44. International Agency for Research on Cancer: IARC Monographs on the evaluation of carcinogenic risks to humans: Alcohol consumption and ethyl carbamate. In., vol. 96. Lyon, France: International Agency for Research on Cancer; 2010.

45. International Agency for Research on Cancer. IARC monographs on the evaluation of carcinogenic risks to humans 100E Personal Habits and Indoor Combustions. Lyon: International Agency for Research on Cancer; 2012.

46. Leoncini E, Carioli G, La Vecchia C, Boccia S, Rindi G. Risk factors for neuroendocrine neoplasms: a systematic review and meta-analysis. Ann Oncol. 2016;27:68-81.

47. Bagnardi V, Rota M, Botteri E, Tramacere I, Islami F, Fedirko V, et al. Alcohol consumption and site-specific cancer risk: a comprehensive dose-response meta-analysis. Br J Cancer. 2015;112:580-93.

48. Rush B. An inquiry into the effects of ardent spirits upon the human body and mind: With an account of the means of preventing, and of the remedies for curing them. 8th edition. Reprint. Richardson: Exeter, N.H; 1785.

49. Rothman KJ, Greenland S, Lash TL. Modern Epidemiology. 3rd ed. Philadelphia: Lippincott Williams \& Wilkins; 2008.

50. Parry C, Rehm J, Poznyak V, Room R. Alcohol and infectious diseases: an overlooked causal linkage? Addiction. 2009;104:331-2.

51. Rehm J, Samokhvalov AV, Neuman MG, Room R, Parry CD, Lönnroth K, et al The association between alcohol use, alcohol use disorders and tuberculosis (TB). A systematic review. BMC Public Health. 2009;9:450.

52. Samokhvalov AV, Irving HM, Rehm J. Alcohol consumption as a risk factor for pneumonia: systematic review and meta-analysis. Epidemiol Infect. 2010; 138:1789-95.

53. Baliunas D, Rehm J, Irving H, Shuper P. Alcohol consumption and risk of incident human immunodeficiency virus infection: a meta-analysis. Int J Public Health. 2010;55:159-66.

54. Parry CDH, Rehm J, Morojele NK. Is there a causal relationship between alcohol and HIV? African J Drug Alcohol Studies. 2010;9:81-92.

55. Fisher JC, Bang H, Kapiga SH. The association between HIV infection and alcohol use: a systematic review and meta-analysis of African studies. Sex Transm Dis. 2007;34:856-63.

56. Gmel G, Shield K, Rehm J. Developing a methodology to derive alcohol-attributable fractions for HIV/AIDS mortality based on alcohol's impact on adherence to antiretroviral medication. Popul Health Metr. 2011;9:5.

57. Rehm J, Shield KD, Joharchi N, Shuper PA. Alcohol consumption and the intention to engage in unprotected sex: systematic review and metaanalysis of experimental studies. Addiction. 2012;107:51-9.

58. Scott-Sheldon LA, Carey KB, Cunningham K, Johnson BT, Carey MP. Alcohol use predicts sexual decision-making: a systematic review and meta-analysis of the experimental literature. AIDS Behav. 2015:Suppl 1:S19-39.

59. Ferreira-Borges C, Rehm J, Dias S, Babor T, Parry CD. The impact of alcohol consumption on African people in 2012: an analysis of burden of disease. Trop Med Int Health. 2016;21:52-60.

60. Kessler RC, Crum RM, Warner LA, Nelson CB, Schulenberg J, Anthony JC. Lifetime co-occurrence of DSM-III-R alcohol abuse and dependence with other psychiatric disorders in the National Comorbidity Survey. Arch Gen Psychiatry. 1997;54:313-21.

61. Regier D, Farmer M, Rae D, Locke B, Keith S, Judd L, et al. Comorbidity of mental disorders with alcohol and other drug abuse: Results from the Epidemiological Catchment Area (ECA) Study. JAMA. 1990;264:2511-8.

62. Helzer JE, Pryzbeck TR. The co-occurrence of alcoholism with other psychiatric disorders in the general population and its impact on treatment. J Stud Alcohol. 1988:49:219-24.

63. Rehm J, Anderson P, Gual A, Kraus L, Marmet S, Room R, et al. The tangible common denominator of substance use disorders: a reply to commentaries to Rehm et al. (2013). Alcohol Alcohol. 2014;49:118-22.

64. Rehm J, Marmet S, Anderson P, Gual A, Kraus L, Nutt DJ, et al. Defining substance use disorders: do we really need more than heavy use? Alcohol Alcohol. 2013;48:633-40.

65. American Psychiatric Association. Diagnostic and statistical manual of mental disorders (5th edition). Philadelphia: American Psychiatric Association; 2013.
66. World Health Organization. ICD-10 Classification of mental and behavioural disorders: with glossary and diagnostic criteria for research. New York: Churchill Livingstone; 1994.

67. Boden JM, Fergusson DM. Alcohol and depression. Addiction. 2011;106:906-14.

68. Foulds JA, Adamson SJ, Boden JM, Williman JA, Mulder RT. Depression in patients with alcohol use disorders: Systematic review and meta-analysis of outcomes for independent and substance-induced disorders. J Affect Disord. 2015;1:47-59.

69. Samokhvalov AV, Irving H, Mohapatra S, Rehm J. Alcohol consumption, unprovoked seizures and epilepsy: a systematic review and meta-analysis. Epilepsia. 2010;51:1177-84.

70. Rehm J, Taylor B, Mohapatra S, Irving H, Baliunas D, Patra J, et al. Alcohol as a risk factor for liver cirrhosis - a systematic review and meta-analysis. Drug Alcohol Rev. 2010;29:437-45.

71. Baliunas D, Taylor B, Irving H, Roerecke M, Patra J, Mohapatra S, et al. Alcohol as a risk factor for type 2 diabetes - A systematic review and meta-analysis. Diabetes Care. 2009;32:2123-32.

72. Roerecke $M$, Rehm J. Alcohol intake revisited: risks and benefits. Curr Atheroscler Rep. 2012:14:556-62.

73. Taylor B, Irving HM, Baliunas D, Roerecke M, Patra J, Mohapatra S, et al. Alcohol and hypertension: gender differences in dose-response relationships determined through systematic review and meta-analysis. Addiction. 2009;104:1981-90.

74. Roerecke M, Rehm J. Alcohol consumption, drinking patterns, and ischemic heart disease: a narrative review of meta-analyses and a systematic review and meta-analysis of the impact of heavy drinking occasions on risk for moderate drinkers. BMC Med. 2014;12:182.

75. Patra J, Taylor B, Irving H, Roerecke M, Baliunas D, Mohapatra S, et al. Alcohol consumption and the risk of morbidity and mortality from different stroke types - a systematic review and meta-analysis. BMC Public Health. 2010;10:258

76. Samokhvalov AV, Irving HM, Rehm J. Alcohol as a risk factor for atrial fibrillation: a systematic review and meta-analysis. Eur J Cardiov Prev R. 2010;17:706-12.

77. Cherpitel C, Ye Y, Bond J, Borges G, Autonoma M, Monteiro M, et al. Alcohol attributable fraction for injury morbidity from the doseresponse relationship of acute alcohol consumption: emergency department data from 18 countries. Addiction. 2015;110:1724-32.

78. Rehm J. Commentary on Cherpitel et al. (2015): improving global estimates of alcohol-attributable injury. Addiction. 2015;110:1733-4.

79. Gell L, Ally A, Buykx P, Hope A, Meier P. Alcohol's harm to others: An Insitute of Alcohol Studies report. United Kingdom: Institute of Alcohol Studies; 2015

80. Laslett AM, Catalano P, Chikritzhs T, Dale C, Doran C, Ferris J, et al. The range and magnitude of alcohol's harm to others. Fitzroy: Turning Point Alcohol \& Drug Centre; 2010

81. Shield KD, Rylett MJ, Gmel G, Rehm J. Trends in alcohol consumption and alcohol-attributable mortality in the EU in 2010. In: World Health Organization Regional Office for Europe, editor. Status report on alcohol and health in 35 European countries. Copenhagen: WHO Regional Office for Europe; 2013.

82. Patra J, Bakker R, Irving H, Jaddoe WW, Malini S, Rehm J. Dose-response relationship between alcohol consumption before and during pregnancy and the risks of low birthweight, preterm birth and small for gestational age (SGA)-a systematic review and meta-analyses. Int J Gynaecol Obstet. 2011;118:1411-21.

83. Shield KD, Parry C, Rehm J. Chronic diseases and conditions related to alcohol use. Alcohol Res. 2013:35:155-71.

84. Shield K, Rehm J. Russia-specific relative risks and their effects on the estimated alcohol-attributable burden of disease. BMC Public Health. 2015;15:482.

85. Shield KD, Soerjomataram I, Rehm J. Alcohol use and breast cancer: a critical review. Alcohol Clin Exp Res. 2016;40:1166-81.

86. Rehm J. Light or moderate drinking is linked to alcohol related cancers, including breast cancer. BMJ. 2015;351:h4400.

87. Corrao G, Bagnardi V, Zambon A, La Vecchia C. A meta-analysis of alcohol consumption and the risk of 15 diseases. Prev Med. 2004;38:613-9.

88. Rehm J, Baliunas D, Borges GL, Graham K, Irving HM, Kehoe T, et al. The relation between different dimensions of alcohol consumption and burden of disease - An overview. Addiction. 2010;105:817-43.

89. Rehm J, Shield KD, Roerecke M, Gmel G. Modelling the impact of alcohol consumption on cardiovascular disease mortality for comparative risk assessments: an overview. BMC Public Health. 2016;16:363. 
90. Roerecke M, Rehm J. Irregular heavy drinking occasions and risk of ischemic heart disease: a systematic review and meta-analysis. Am J Epidemiol. 2010; 171:633-44.

91. Mostofsky E, van der Bom JG, Mukamal KJ, Maclure M, Tofler M, Tofler GH, et al. Risk of myocardial infarction immediately after alcohol consumption. Epidemiology. 2015;26:143-50.

92. Marmot MG, Shipley MJ, Rose G, Thomas B. Alcohol and mortality: a U-shaped curve. Lancet. 1981;317:580-3.

93. European Association for the Study of the Liver. EASL clinical practical guidelines: management of alcoholic liver disease. J Hepatol. 2012;57:3399-420.

94. Lachenmeier DW, Kanteres F, Rehm J. Epidemiology-based risk assessment using the benchmark dose/margin of exposure approach: the example of ethanol and liver cirrhosis. Int J Epidemiol. 2011;40:210-8.

95. Rehm J, Roerecke M. Patterns of drinking and liver cirrhosis - what do we know and where do we go? J Hepatol. 2015;62:1061-7.

96. Sindelar H, Barnett N, Spirito A. Adolescent alcohol use and injury. A summary and critical review of the literature. Minerva Pediatr. 2004:56:291-309.

97. Rehm J, Gmel G, Sempos C, Trevisan M. Alcohol-related mortality and morbidity. Alcohol Res Health. 2003;27:39-51.

98. Zaridze D, Brennan P, Boreham J, Boroda A, Karpov R, Lazarev A, et al. Alcohol and cause-specific mortality in Russia: a retrospective case-control study of 48,557 adult deaths. Lancet. 2009;373:2201-14.

99. Zaridze D, Lewington S, Boroda A, Scélo G, Karpov R, Lazarev A, et al. Alcohol and mortality in Russia: prospective observational study of 151,000 adults. Lancet. 2014;383:1465-73.

100. Rehm J. What can we learn from Russia about alcohol epidemiology and alcohol policy? Lancet. 2014;383:1440-2

101. Room R, Jernigan D, Carlini BH, Gmel G, Gureje O, Mäkelä K, et al El alcohol y los países en desarrollo. Una perspectiva de salud pública. Mexico: Organización Panamericana de la Salud \& Fondo de Cultura Económica; 2013.

102. Rehm J, Monteiro M, Room R, Gmel G, Jernigan D, Frick U, et al. Steps towards constructing a global comparative risk analysis for alcohol consumption: Determining indicators and empirical weights for patterns of drinking, deciding about theoretical minimum, and dealing with different consequences. Eur Addict Res. 2001;7:138-47.

103. Brooks PJ, Enoch MA, Goldman D, Li TK, Yokoyama A. The alcohol flushing response: an unrecognized risk factor for esophageal cancer from alcohol consumption. PLoS Med. 2009;6:258-63.

104. Roerecke M, Shield KD, Higuchi S, Yoshimura A, Larsen E, Rehm MX, et al. Estimates of alcohol-related oesophageal cancer burden in Japan: systematic review and meta-analyses. Bull World Health Org. 2015;93:329-338c.

105. Murray CJL, Ezzati M, Lopez AD, Rodgers A, Vander HS. Comparative quantification of health risks: conceptual framework and methodological issues. In: Ezzati M, Lopez AD, Rodgers A, Murray CJL, editors. Comparative Quantification of Health Risks: Global and regional Burden of Disease attributable to selected major risk factors. Geneva: World Health Organization; 2004. p. 1-38.

106. Vander Hoorn S, Ezzati M, Rodgers A, Lopez AD, Murray CJL. Estimating attributable burden of disease from exposure and hazard data. In: Ezzati M, Lopez AD, Rodgers A, Murray CJL, editors. Comparative Quantification of Health Risks: Global and Regional Burden of Disease Attributable to Selected Major Risk Factors. Geneva: World Health Organization; 2004. p. 2129-40.

107. Walter SD. The estimation and interpretation of attributable risk in health research. Biometrics. 1976;32:829-49.

108. Walter SD. Prevention of multifactorial disease. Am J Epidemiol. 1980;112:409-16.

109. Murray CJL, Lopez A. On the comparable quantification of health risks: lessons from the global burden of disease study. Epidemiology. 1999;10: 594-605.

110. Rehm J, Kehoe T, Gmel G, Stinson F, Grant B, Gmel G. Statistical modeling of volume of alcohol exposure for epidemiological studies of population health: the example of the US. Popul Health Metr. 2010;8:3.

111. Rehm J, Klotsche J, Patra J. Comparative quantification of alcohol exposure as risk factor for global burden of disease. Int J Methods Psychiatr Res. 2007; 16:66-76.

112. Kehoe T, Gmel Jr G, Shield K, Gmel Sr G, Rehm J. Determining the best population-level alcohol consumption model and its impact on estimates of alcohol-attributable harms. Popul Health Metr. 2012;10:6

113. Gmel G, Rehm J. Measuring alcohol consumption. Contemp Drug Probl. 2004;31:467-540
114. Poznyak V, Fleischmann A, Rekve D, Rylett M, Rehm J, Gmel G. The World Health Organization's Global monitoring system on alcohol and health. Alcohol Res. 2013;35:244-9.

115. Midanik LT. The validity of self-reported alcohol consumption and alcohol problems: a literature review. Br J Addict. 1982;77:357-82

116. Midanik L. Validity of self-reported alcohol use: a literature review and assessment. Br J Addict. 1988;83:1019-29.

117. Shield K, Kehoe T, Taylor B, Patra J, Rehm J. Alcohol-attributable burden of disease and injury in Canada, 2004. Int J Public Health. 2012;57:391-401.

118. Ramstedt M. How much alcohol do you buy? A comparison of self-reported alcohol purchases with actual sales. Addiction. 2010;105:649-54.

119. Ministry of Health. Alcohol Use in New Zealand: Key results of the 2007/08 New Zealand Alcohol and Drug Use Survey. Wellington: Ministry of Health; 2009.

120. King AC. Enhancing the self-report of alcohol consumption in the community: two questionnaire formats. Am J Public Health. 1994;84:294-6.

121. Willett W. Nutritional epidemiology. Oxford: Oxford University Press; 2012.

122. Giovannucci E, Colditz G, Stampfer MJ, Rimm EB, Litin L, Sampson L, et al. The assessment of alcohol consumption by a simple self-administered questionnaire. Am J Epidemiol. 1991;133:810-7.

123. Shield K, Rehm J. Difficulties with telephone-based surveys on alcohol in high-income countries: the Canadian example. Int J Methods Psychiatr Res. 2012;21:17-28.

124. Rey G, Boniol M, Jougla E. Estimating the number of alcohol-attributable deaths: methodological issues and illustration with French data for 2006. Addiction. 2010;105:1018-29.

125. Rehm J. Commentary on Rey et al. (2010): How to improve estimates on alcohol-attributable burden? Addiction. 2010;105:1030-1.

126. Holmes J, Meier PS, Booth A, Guo Y, Brennan A. The temporal relationship between per capita alcohol consumption and harm: a systematic review of time lag specifications in aggregate time series analyses. Drug Alcohol Depend. 2012;123:7-14.

127. Rehm J. Alcohol consumption and mortality. What do we know and where should we go? Addiction. 2000;95:989-95

128. Kontis V, Mathers CD, Rehm J, Stevens GA, Shield KD, Bonita R, et al. Contribution of six risk factors to achieving the " $25 \times 25$ " NCD mortality reduction target. Lancet. 2014;384:427-37.

129. Kontis V, Mathers CD, Bonita R, Stevens GA, Rehm J, Shield KD, et al. Regional contributions of six preventable risk factors to achieving the $25 \times 25$ non-communicable disease mortality reduction target: a modelling study. Lancet Global Health. 2015;3:e746-57.

130. Gmel G, Kuntsche E, Rehm J. Risky single occasion drinking: bingeing is not bingeing. Addiction. 2011;106:1037-45.

131. Gmel G, Kuntsche E, Rehm J. Risky single occasion drinking research: the four stages of enlightenment. Addiction. 2011;106:1050-1.

132. Praud D, Rota M, Rehm J, Shield K, Zatonski W, Hashibe M, et al. Cancer incidence and mortality attributable to alcohol consumption. Int J Cancer. 2016;138:1380-7.

133. Gmel G, Rehm J. Harmful alcohol use. Alcohol Res Health. 2003;27:52-62.

134. Roberts $H$, Meddings D. Violence and unintentional injury: equity and social determinants. In: Blas E, Kurup AS, editors. Equity, social determinants and public health programmes. Geneva: World Health Organization; 2010. p. 243-59.

135. Room R, Ferris J, Laslett AM, Livingston M, Mugavin J, Wilkinson C. The drinker's effect on the social environment: a conceptual framework for studying alcohol's harmto others. Int J Environ Res Public Health. 2010;7:1855-71.

136. World Health Organization. Global status report on road safety 2015. Geneva: World Health Organization; 2015.

137. Lange S, Probst C, Heer N, Roerecke M, Rehm J, Monteiro MG et al. Actual and predicted prevalence of alcohol consumption during pregnancy in Latin America and the Caribbean: systematic literature review and metaanalysis. Revista Panamericana de Salud Pública/Pan American Journal of Public Health. 2016; epub ahead of print

138. Popova S, Lange S, Probst C, Gmel G, Rehm J. Estimation of national, regional and global prevalence of alcohol use during pregnancy and fetal alcohol syndrome: a systematic review and meta-analysis. Toronto: Centre for Addiction and Mental Health; 2016.

139. Kamerstuk - Eerste Kamer der Staten-General. 33799 Wijziging van het Wetboek van Strafvordering in verband met de introductie van de bevoegdheid tot het bevelen van een middelenonderzoek bij geweldplegers en enige daarmee samenhangende wijzigingen van de Wegenverkeerswet 1994 [33 799 Amendment of the Code of Criminal 
Procedure in connection with the introduction of the power to recommend an agent study of violent offenders and any related amendments to the Road Traffic Act 1994]. Netherlands: Verheid; 2016.

140. Babor T, Caetano R, Casswell S, Edwards G, Giesbrecht N, Graham K, et al. Alcohol: No ordinary commodity. Research and public policy. 2nd edition. Oxford and London: Oxford University Press; 2010.

141. Anderson P, Chisholm D, Fuhr D. Effectiveness and cost-effectiveness of policies and programmes to reduce the harm caused by alcohol. Lancet. 2009:373:2234-46.

142. World Health Organization. Global Action Plan for the Prevention and Control of NCDs 2013-2020. Geneva: World Health Organization; 2013.

143. World Economic Forum \& World Health Organization. From burden to "best buys": Reducing the economic impact of non-communicable diseases in low- and middle-income countries. Davos: World Economic Forum; 2011.

144. Rabinovich L, Brutscher PB, de Vries H, Tiessen J, Clift J, Reding A. The affordability of alcoholic beverages in the European Union: Understanding the link between alcohol affordability, consumption and harms. 2009. RAND Europe.

145. Rehm J, Lachenmeier DW, Jané Llopis E, Imtiaz S, Anderson P. Evidence of reducing ethanol content in beverages to reduce harmful use of alcohol. Lancet Gastroenterol Hepatol. 2016;1:78-83.

146. Rehm J, Shield KD, Rehm MX, Gmel G, Frick U. Modelling the impact of alcohol dependence on mortality burden and the effect of available treatment interventions in the European Union. Eur Neuropsychopharmacol. 2013;23:89-97.

147. Purshouse CR, Meier PS, Brennan A, Taylor KB, Rafia R. Estimated effect of alcohol pricing policies on health and health economic outcomes in England: an epidemiological model. Lancet. 2010;375:1355-64.

148. Holmes J, Meng Y, Meier PS, Brennan A, Angus C, Campbell-Burton A, et al. Effects of minimum unit pricing for alcohol on different income and socioeconomic groups: a modelling study. Lancet. 2014;383:1655-64.

149. Health and Safety Executive. Don't mix it: A guide for employers on alcohol at work. United Kingdom: Crown; 1996.

150. Rehm J, Zatonski W, Taylor B, Anderson P. Epidemiology and alcohol policy in Europe. Addiction. 2011;106:11-9.

151. Killoran A, Canning U, Doyle N, Sheppard L. Centre for Public Health Excellence NICE 2010 Review of effectiveness of laws limiting blood alcohol concentration levels to reduce alcohol-related road injuries anddeaths. http://www.ias.org.uk/uploads/pdf/bloodalcoholcontenteffectivenessreview. pdf. Accessed 22 Oct 2016.

152. Rehm J, Samokhvalov AV, Shield KD. Global burden of alcoholic liver diseases. J Hepatol. 2013;59:160-8.

153. Zatonski W, Sulkowska U, Manczuk M, Rehm J, Lowenfels AB, La Vecchia C. Liver cirrhosis mortality in Europe, with special attention to central and eastern Europe. Eur Addict Res. 2010;16:193-201.

154. Rehm J, Taylor B, Patra J, Gmel G. Avoidable burden of disease: conceptual and methodological issues in substance abuse epidemiology. Int J Methods Psychiatr Res. 2006;15:181-91.

155. Murray CIL, Lopez A. Global mortality, disability, and the contribution of risk factors: global burden of disease study. Lancet. 1997;349:1436-42.

156. Ezzati M, Lopez AD, Rodgers AD, Vander Horn S, Murray CJL, Comparative Risk Assessment Collaborating Group. Selected major risk factors and global and regional burden of disease. Lancet. 2002;360:1347-60.

157. Rehm J, Mathers C, Popova S, Thavorncharoensap M, Teerawattananon Y, Patra J. Global burden of disease and injury and economic cost attributable to alcohol use and alcohol use disorders. Lancet. 2009;373:2223-33.

158. Lönnroth K, Williams B, Stadlin S, Jaramillo E, Dye C. Alcohol use as a risk factor for tuberculosis - a systematic review. BMC Public Health. 2008;8:289.

159. Roerecke M, Rehm J. The cardioprotective association of average alcohol consumption and ischaemic heart disease: a systematic review and meta-analysis. Addiction. 2012:107:1246-60.

\section{Submit your next manuscript to BioMed Central and we will help you at every step:}

- We accept pre-submission inquiries

- Our selector tool helps you to find the most relevant journal

- We provide round the clock customer support

- Convenient online submission

- Thorough peer review

- Inclusion in PubMed and all major indexing services

- Maximum visibility for your research

Submit your manuscript at www.biomedcentral.com/submit
Biomed Central 